\title{
Nutritional Knowledge, Attitude and Practice among Antenatal and Postnatal Mothers in Hospital Tengku Ampuan Afzan (Htaa), Kuantan, Pahang 2016
}

\author{
Liyana Nabihah Ikhsan ${ }^{1}$,Nur Asifa Mohd Nasaruddin ${ }^{1}$, Farhana Othman ${ }^{1}$, Karimah Hanim Abd Aziz ${ }^{2}$, Hamizah \\ Ismail ${ }^{1}$. \\ Department of Obstetrics and Gynaecology, Kuliyyah of Medicine, International Islamic University Malaysia, \\ Kuantan, Pahang, Malaysia ${ }^{2}$ Department of Community Medicine, Kuliyyah of Medicine, International Islamic \\ University Malaysia, Kuantan, Pahang.
}

\begin{abstract}
Background: Balanced and sufficient maternal nutritional intake ensures not only the wellbeing of pregnant mother, fetus, and newborn (protection of life) but also her future health and her three generations (protection of progeny). Nutritional inadequacies during pregnancy have been reported and several factors were attributed. The objectives were to measure nutritional knowledge, attitude, and practice (KAP) during pregnancy and the relationship with socio-demographic characteristics. Methods: A cross-sectional study was conducted among 320 antenatal and postnatal mothers in Hospital Tengku Ampuan Afzan (HTAA), Pahang, Malaysia from $18^{\text {th }}$ July to $27^{\text {th }}$ August 2016. A pre-tested self-constructed, interview-guided questionnaire was used. Independent variables were age, ethnicity, educational level, marital status, and monthly household income. Outcomes were nutritional KAP-level with median used for the categorization. The relationship between independent variables and outcomes was obtained by logistic regression with significance at $p<0.05$. Results: Sixty-five percent aged from 25 to $34,84 \%$ Malays, $37 \%$ completed secondary education with SPM/O-level, $96 \%$ married, $48 \%$ from middle-income family, $52 \%$ had a good nutritional knowledge, $67 \%$ with a positive attitude and $55 \%$ with good practice. Age and educational level were significantly related to knowledge. The only educational level was significantly related to practice. Less than $70 \%$ of respondents have good nutritional KAP, reflected by educational level with more than half of them received up to secondary education. Hence, the rights of mothers in getting a necessary and adequate education should be fulfilled. Conclusion: Results emphasize the importance of empowering girls and women with adequate educations and to strengthen the nutritional and health education of our educational system. It is for them to be knowledgeable with good attitude and practicing healthy nutritional lifestyle as they entering reproductive life, maintaining and transferring at least optimum healthy life to their progenies.
\end{abstract}

KEYWORDS: Nutrition, knowledge, attitude, practice, pregnancy

\section{INTRODUCTION}

Balanced and sufficient maternal intake of macronutrients and micronutrients ensures not only the health status of the pregnant mother, the wellbeing of the fetus and the newborn but future health status of herself (protection of life) and her three generations (protection of progeny). ${ }^{1-3}$ Besides, poor and excessive nutrition of pregnant women may lead to maternal morbidity and mortality. ${ }^{4-6}$ Nutritional imbalance causes failure of the fetus to reach its full growth potential known as fetal growth restriction (FGR), which is associated with child both short and long term complications, mortality and mortality. ${ }^{4,7,8}$ Hence, an optimal level of nutritional consumption is crucial for the maintenance of positive maternal and fetal health for a good course and outcome of pregnancy.,

Liyana Nabihah Ikhsan

Department of Obstetrics and Gynaecology,

Kulliyyah of Medicine,

International Islamic University,

Kuantan Campus.

Email: liyanaikhsan@gmail.com
The incidence of dietary inadequacies as a result of dietary habits and patterns in pregnancy is higher than at any other phase of the life. ${ }^{11}$ During pregnancy, nutritional knowledge, attitude, and practice (KAP) of the mother can be either good or poor. Slightly more than half of pregnant women in a public hospital in Malawi, South-eastern Africa had knowledge about nutrition and food groups. ${ }^{12}$ In other third world countries, the majority had poor nutritional knowledge. ${ }^{2,3,13}$ In Ukhia, Bangladesh, most of the antenatal and postnatal mothers have poor knowledge on nutrition. ${ }^{14}$ Meanwhile, a study in private hospitals in Klang Valley, Malaysia revealed pregnant women had moderate nutritional knowledge score. ${ }^{15}$ Regarding nutritional attitude, a study in Japan suggested that pregnant women are aware of the need to adopt healthy behaviours. ${ }^{16}$ However, these findings were different to a study that reported pregnant mothers have a poor attitude during pregnancy. ${ }^{13}$ Numerous studies revealed that majority of pregnant mothers practiced poor intake of nutrients during pregnancy. ${ }^{7,13}$ 
Several studies found that the older age group, White people, married people, higher educational level and higher income are associated with higher nutritional knowledge score.Income, educational background, and older maternal age was significantly associated with a positive attitude towards diet as proven by a nutritional KAP study done previously. Income differences were also agreed as a factor that may influence dietary practices, in which pregnant women with a higher range of household income are more likely to have good nutritional practice.Nutritional practice is healthier among African-American compared with White women, however young age, low education, and poverty had the poorer nutritional intake.

Nutritional knowledge will affect nutritional attitude and practice in pregnancy.It was shown in these studies that the understanding of diet-disease relationships would lead to good attitudes and favourable food choices. ${ }^{23,30-33}$ In contrary, there are also studies, which showed that there was no association between nutritional knowledge and dietary habits. ${ }^{34-36}$ The attitude was shown to have a strong association with good practices during pregnancy. ${ }^{13,25}$ Consequently, optimum maternal and child health could be attained by encouraging proper nutritional attitude and practice during pregnancy. ${ }^{33}$

Studies about nutritional KAP are still lacking in our population especially among pregnant mothers. ${ }^{37,38}$ Therefore, we are interested to know about nutritional KAP during pregnancy in our setting particularly in Hospital Tengku Ampuan Afzan (HTAA), Kuantan, Pahang to be compared with previous studies done. We also would like to investigate if there is an interrelation between nutritional KAP and relate them to sociodemographic characteristics of respondents.

Apart from there is no study done yet reflecting general population in Malaysia as it is done in public hospital, we could also help in providing a baseline data for intervention and education program to be initiated as early as before embarking the pregnancy period.

\section{MATERIALS AND METHOD}

Based on 2015's data, the average number of pregnant mothers who gave birth in HTAA in a month was 800 . Applying single proportion formula, when $95 \%$ confidence interval is desired among 800 patients, based on 5\% of precision, the minimum sample size required was 261 . After considering $20 \%$ of the non-response rate and finite population correction, the minimum sample size required was 314. A cross-sectional study was conducted and 320 antenatal and postnatal mothers in Hospital Tengku Ampuan Afzan (HTAA), Pahang, Malaysia was sampled by using quota sampling method from $18^{\text {th }}$ July to $27^{\text {th }}$ August 2016.

The inclusion criteria are a Malaysian citizen, 18 years of age and older, and pregnant mothers of 28 weeks gestation up to term until 2 weeks postnatal. Exclusion criteria are those with a diagnosis of complications in pregnancy, specifically Diabetes (Diabetes Complicating Pregnancy, Gestational Diabetes Mellitus) and Hypertension (Pregnancy Induced Hypertension, Hypertension Complicating Pregnancy, Pre-eclampsia, Impending Eclampsia), do not understand Malay or English Language and refuse to participate in the study.

Data collection was from $18^{\text {th }}$ to $28^{\text {th }}$ July 2016 . An ethical approval was obtained from Medical Research and Ethics Committee of Ministry of Health Malaysia, IIUM Research Ethics Committee, and Ethical Committee of Kuliyyah of Medicine, IIUM.

\section{Instruments}

The participants' socio-demographic characteristics and nutritional KAP were assessed with a pre-tested self-constructed questionnaire that was developed in the Malay language by referring the Guidelines for assessing nutrition-related KAP released by Nutrition Division of the Food and Agriculture Organization of the United Nations (FAO), 2014. Interview-guided questionnaire and information from the antenatal record were required as some of the patients were anticipated to be illiterate and it helps to minimize missing data in this study.

The questionnaire comprises 62 questions. The questions were made into three sections. Section A consists of socio-demographic characteristics with 6 items; age, gender, race, marital status, educational level, and monthly household income were adapted from a study done in Ethiopia. ${ }^{13}$ Section B is regarding antenatal characteristics with 10 items, requiring the interviewers to obtain the data from the antenatal home-based card; height, current gestational age and at booking, weight at booking, and current body weight/just before delivery for post-natal mothers. Section $C$ is nutritional KAP with 46 items that were adapted from several previous studies to suit the local setting and culture. ${ }^{19,25,36,39}$ It can be further divided into three domains; 19 items for knowledge, 14 items for attitude, and 13 items for practice. Each of the domains was targeted to assess their KAP in three main components of nutrition in pregnancy (macronutrients, micronutrients, and other dietary concerns).

All questions were coded and arranged so as to ease both interviewer and respondents. Each question of nutritional KAP has 2 to 4 response options. One (1) mark was assigned to a correct option while zero (0) mark was given for incorrect option. Those who answered 'not sure' were recorded as incorrect. We used median and interquartile range to analyze each domain.

\section{Statistical Analysis}

Data was analyzed using IBM SPSS version 23.0 for Windows (SPSS Inc., Chicago, IL). The data was explored to look for any outliers or missing data. The socio-demographic, antenatal characteristics 
and nutritional KAP of the respondents were analyzed using descriptive statistics. Frequency and percentage of each demographic data, namely age, race, marital status, educational level, and total monthly income were described. KAP scores were assessed by using median and inter-quartile range. Those with the scores above the median will be categorized as good KAP while those with scores below the median will be categorized as poor KAP. Chi-square test was used to evaluate the relationship between nutritional KAP. The factors were known to be significantly important when its $\mathrm{p}$-value $<0.05$. Binary logistic regression analysis was used to explore the relationship of sociodemographic characteristics with nutritional KAP.

\section{RESULTS}

The socio-demographic characteristics of the respondents are presented in Table 1. A total of 320 mothers participated in this survey. Majority of the respondents were between 25 to 34 years old $(65 \%)$, in the postnatal period $(64 \%)$, Malay $(84 \%)$, completed secondary education with SPM/O-level

Table 1: Socio-demographic characteristics of respondents $(\mathrm{N}=320)$

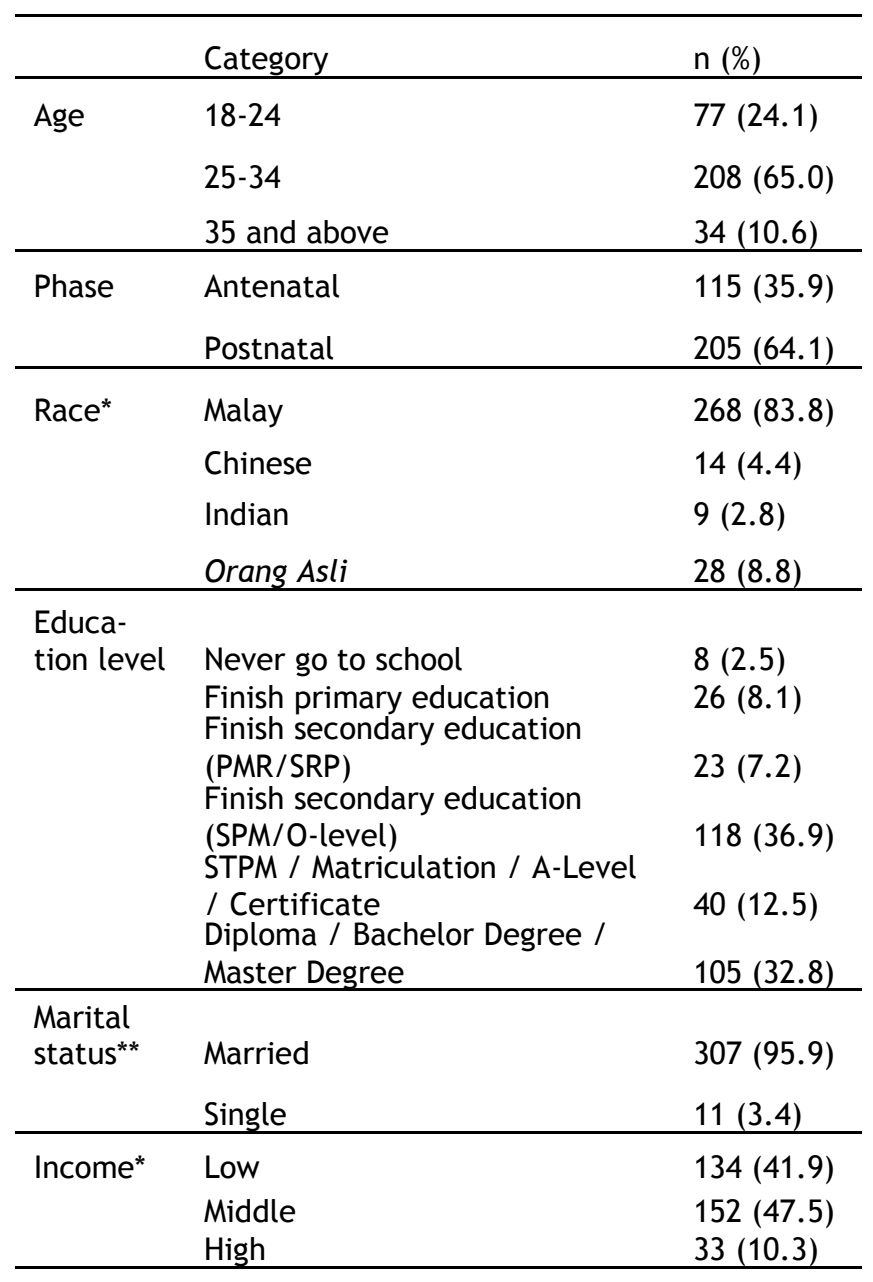

Missing data $=1$, Missing data $=2$

(37\%) and married (96\%). About $48 \%$ of respondents were from middle household income. Marginally more than half of total respondents have good nutritional knowledge (52\%), good nutritional attitude (67\%) and good nutritional practice (55\%) during pregnancy.
In this study, among the socio-demographic characteristics that have significantly related with nutritional knowledge are age group ( $\mathrm{p}$-value = 0.019 ) and education level ( $p$-value <0.001), as shown in Table 2. Respondents with 35 years old age and above are four times more likely to be knowledgeable on nutrition during pregnancy as compared to those in 18-24 years old group respondents $\quad(\mathrm{OR}=3.54,95 \% \quad \mathrm{Cl}$ : 1.23-10.20). Meanwhile, respondents with high education (diploma/ bachelor degree/ master's degree) are 23 times more likely to have better knowledge on nutrition in pregnancy as compared to those with education up to primary school level (OR=23.20, 95\% $\mathrm{Cl}$ : 6.08-88.44). However, there is no single significant relationship between all of the sociodemographic characteristics with nutritional attitude as shown in Table 3.

Table 2: Relationship between socio-demographic and nutritional knowledge

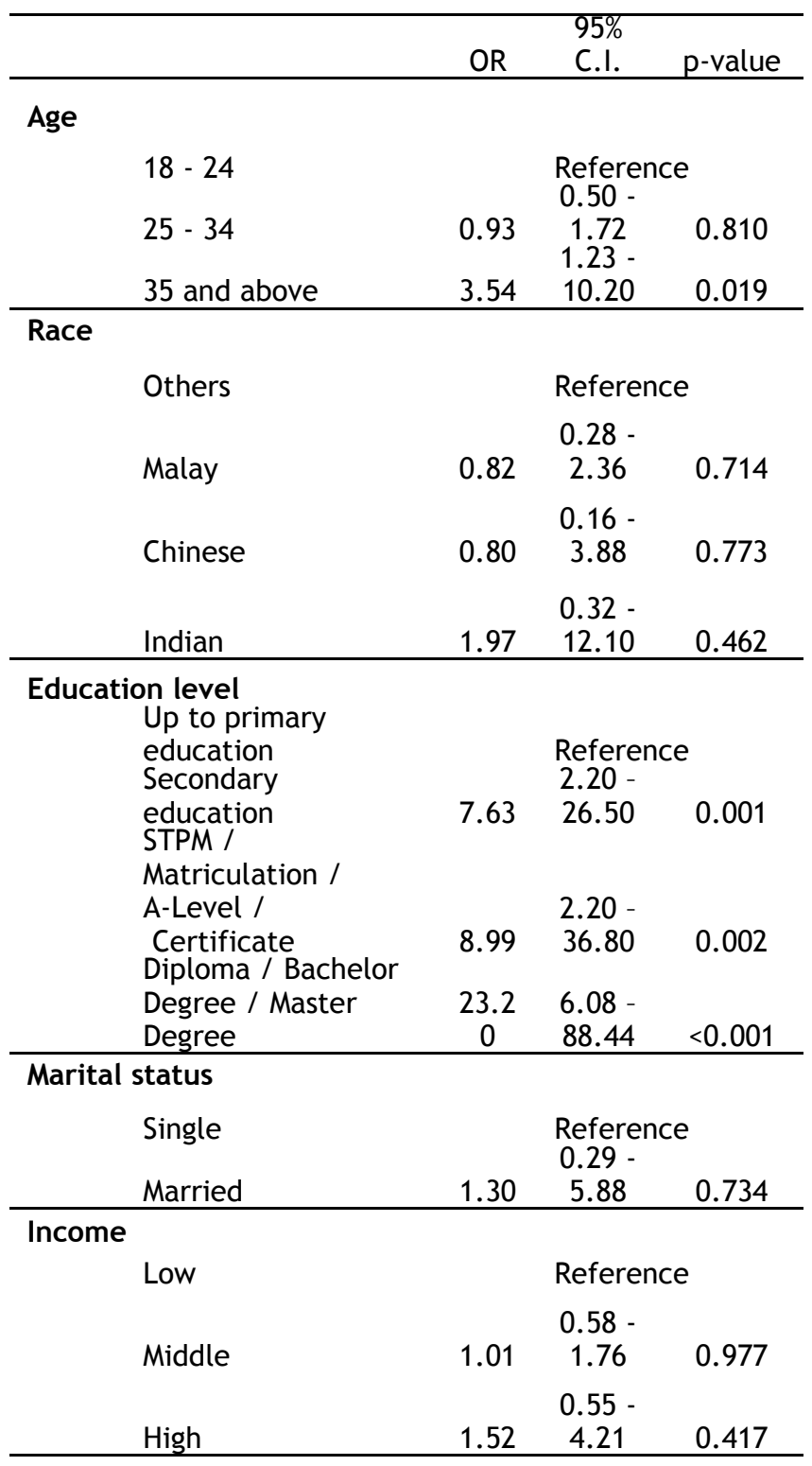

Missing data $=5$ 
Table 3: Relationship between socio-demographic with nutritional attitude

\begin{tabular}{|c|c|c|c|}
\hline & OR & $\begin{array}{l}95 \% \\
\text { C.I. }\end{array}$ & $\begin{array}{l}\mathrm{p}- \\
\text { value }\end{array}$ \\
\hline \multicolumn{4}{|l|}{ Age } \\
\hline $18-24$ & \multicolumn{2}{|c|}{ Reference } & \\
\hline $25-34$ & 0.99 & & 0.981 \\
\hline 35 and above & 2.30 & 6.59 & 0.120 \\
\hline
\end{tabular}

Race

\begin{tabular}{llll} 
Others & \multicolumn{3}{c}{ Reference } \\
& \multicolumn{3}{c}{$0.66-$} \\
Malay & 1.68 & 4.29 & 0.277 \\
& & $0.56-$ & \\
Chinese & 3.02 & 16.16 & 0.197 \\
& & $0.61-$ & \\
Indian & 3.65 & 21.80 & 0.155 \\
\hline
\end{tabular}

Education level

\begin{tabular}{|c|c|c|c|}
\hline Up to primary education & Refe & nce & \\
\hline Secondary education & 1.25 & $\begin{array}{l}0.50- \\
3.17\end{array}$ & 0.635 \\
\hline $\begin{array}{l}\text { STPM / Matriculation / } \\
\text { A-Level / Certificate }\end{array}$ & 2.29 & $\begin{array}{l}0.70- \\
7.48\end{array}$ & 0.169 \\
\hline $\begin{array}{l}\text { Diploma / Bachelor De } \\
\text { gree / Master Degree }\end{array}$ & 2.59 & $\begin{array}{l}0.91- \\
7.38\end{array}$ & 0.076 \\
\hline
\end{tabular}

Martial status

\begin{tabular}{lccc} 
Single & \multicolumn{3}{c}{ Reference } \\
& \multicolumn{3}{c}{$0.27-$} \\
Married & 1.07 & 4.24 & 0.924 \\
\hline
\end{tabular}

Income

\begin{tabular}{|c|c|c|c|}
\hline Low & Ref & rence & \\
\hline Middle & & $\begin{array}{l}0.62- \\
1.94\end{array}$ & 0.747 \\
\hline High & 1.19 & $\begin{array}{l}0.43- \\
3.33\end{array}$ & 0.738 \\
\hline
\end{tabular}

Missing data $=4$

Based on Table 4,only educational level has asignificant relationship with nutrition practice during pregnancy $(p-v a l u e=0.012)$, whereas, age, race, marital status and income of the respondents have no relationship with nutritional practice during pregnancy.Those who had a high education (diploma/ bachelor degree/masters degree) are four times more likely have good nutritional practice during pregnancy than who had finished the education only up to primary education $(\mathrm{OR}=3.89$, 95\% Cl: 1.35-11.21).
Table 5 shows more than half $(61 \%)$ of those with good nutritional knowledge is more likely had a good attitude towards nutrition in pregnancy. In congruence with this, (65\%) of those with poor knowledge had a poor nutritional attitude $(p<0.001)$ .Similarly, there is a significant relationship between knowledge and practice $(p=0.003)$ in which more women with good knowledge has good nutritional practice in pregnancy (59\%). However, the nutritional attitude was not significantly related to nutritional practice $(p=0.071)$ as shown in Table 6 .
Table 4: Relationship between socio-demographic and nutritional practice

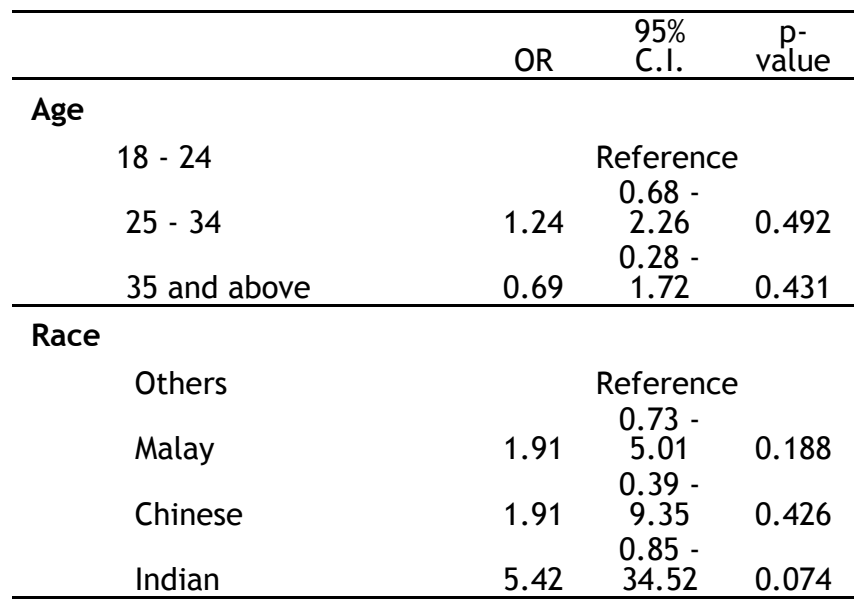

Education level

Up to primary education

Reference

Secondary education STPM / Matriculation/ $\quad 2.06 \quad 5.39$ $\begin{array}{lll}\text { A-Level / Certificate } & 2.28 & \mathbf{7 . 4 2}\end{array}$ Diploma / Bachelor De- $\quad 1.35$ gree / Master Degree

$3.89 \quad 11.21 \quad 0.012$

\section{Marital status}

Single

Married

Reference

\begin{tabular}{ll}
$1.30 \quad 4.82$ \\
\hline
\end{tabular}

0.693

Income

\begin{tabular}{lccc} 
Low & \multicolumn{3}{c}{ Reference } \\
Middle & $0.40-$ & \\
& 0.70 & 1.22 & 0.209 \\
High & 0.84 & $0.33-$ & \\
& 0.11 & 0.707 \\
\hline
\end{tabular}

Missing data $=14$

Table 5: Relationship nutritional knowledge with attitude and practice

\begin{tabular}{|c|c|c|c|c|c|c|c|c|}
\hline & \multicolumn{4}{|c|}{ Nutritional Attitude } & \multicolumn{4}{|c|}{ Nutritional Practice* } \\
\hline & $\begin{array}{l}\text { Good, n } \\
(\%)\end{array}$ & $\begin{array}{l}\begin{array}{l}\text { Poor, } n \\
(\%)\end{array} \\
(\%)\end{array}$ & $a^{2}(d f)$ & $\mathrm{p}$-value & Good, n (\%) & $\begin{array}{l}\text { Poor, } n \\
(\%)\end{array}$ & $a^{2}(d f)$ & p value \\
\hline \multicolumn{9}{|l|}{$\begin{array}{l}\text { Nutritional } \\
\text { Knowledge }\end{array}$} \\
\hline Good & $129(60.8)$ & $37(34.6)$ & $19.66(1)$ & $<0.001$ & $99(58.9)$ & $59(42.1)$ & $\begin{array}{l}8.612 \\
\text { (1) }\end{array}$ & 0.003 \\
\hline Poor & $83(39.2)$ & $70(65.4)$ & & & $69(41.1)$ & $81(57.9)$ & & \\
\hline
\end{tabular}


Table 6: Relationship nutritional attitude with practice

\begin{tabular}{cllll}
\hline \multicolumn{5}{c}{ Nutritional Practice* } \\
\hline & $\begin{array}{l}\text { Good, } \mathrm{n} \\
(\%)\end{array}$ & $\begin{array}{l}\text { Poor, } \\
\mathrm{n}(\%)\end{array}$ & $\begin{array}{l}\mathrm{a}^{2} \\
\text { (df) }\end{array}$ & $\mathrm{p}$-value \\
\hline $\begin{array}{r}\text { Nutritional } \\
\text { Attitude }\end{array}$ & & & & \\
Good & $\begin{array}{l}118 \\
(69.8)\end{array}$ & $\begin{array}{l}84 \\
(60.0)\end{array}$ & $\begin{array}{l}3.263 \\
(1)\end{array}$ & 0.071 \\
& $\begin{array}{l}51 \\
(30.2)\end{array}$ & $\begin{array}{l}56 \\
(40.0)\end{array}$ & & \\
Poor & & & & \\
\hline
\end{tabular}

*Missing data $=10$

\section{DISCUSSION}

Balanced and sufficient maternal intake of macronutrients and micronutrients ensures not only the health status of the pregnant mother, the wellbeing of the fetus and the newborn but future health status of the mother. Her newborn would have an epigenetic transformation, which can be transferred to her other three generations, as explained by Barker Hypothesis. ${ }^{1,40,41}$

The majority of our respondents were between 25 to 34 years old $(65 \%)$, in the postnatal period $(64 \%)$, Malay (84\%), do not enter tertiary education (67\%), married (96\%), and about $90 \%$ of the respondents had income up to middle-household income. Thus, our results mainly from both low and middle socioeconomic background respondents' insights.

Marginally more than half $(52 \%)$ of our respondents have good nutritional knowledge during pregnancy. From our literature review, we found that this is much affected by where and in whom studies were performed. A study in private hospitals in Klang Valley, Malaysia revealed the majority of pregnant women had moderate nutritional knowledge score. ${ }^{15}$ In a public hospital in Malawi, a country in southeastern Africa, $70 \%$ of the pregnant women had knowledge about nutrition and food groups. ${ }^{12}$ However, in other third world countries, the majority had poor nutritional knowledge.,3,13 In Ukhia, Bangladesh, most of the antenatal and postnatal mothers have poor knowledge on nutrition. ${ }^{14}$

Our study pointed out that generally, more than half $(67 \%)$ of overall respondents have a good nutritional attitude during pregnancy. A study in Japan suggested that pregnant women are aware of the need to adopt healthy behaviours whereas a study in Ethiopia reported majority have a poor nutritional attitude during pregnancy. ${ }^{13,16}$

In general, only marginally more than half (55\%) of respondents have good nutritional practice during pregnancy, similar to previous studies revealed that most of the pregnant women were found to have poor nutritional practice during pregnancy. ${ }^{7,13}$

We found that being 35 years old or older are four times more likely to be knowledgeable on nutrition during pregnancy as compared to those in younger age group, which was consistent with several previous studies. ${ }^{17,20,22}$ Respondents with a diploma and higher education are 23 times more likely to have better knowledge on nutrition during pregnancy as compared to those with respondents with education up to primary school level, which was consistent with previous studies. ${ }^{17-22}$

However, we found no single significant relationship betweenall of the socio-demographic characteristics studied with nutritional attitude. However, previous studies found several factors such as older maternal age, ethnicity, income and educational background may influence the nutritional attitude of a pregnant mother. ${ }^{24,25,42}$

Educational level has a significant relationship with nutritional practices among pregnant women in our study. Respondents who hold a diploma or higher education level were more likely to have good practices and this is supported by several other studies. ${ }^{13,25}$ Nevertheless, other socio-demographic determinants were not significantly related to nutritional practices in our study.

Nutritional knowledge has a statistically significant relationship with attitude. Most of the respondents with good nutritional knowledge show the good attitude towards nutrition during pregnancy, in tune with the findings from several studies. ${ }^{13,22}$

Knowledge was also significantly related to nutritional practices in our findings, which is consistent with a number of previous literature. ${ }^{23,30-}$ 33 However, this is contradicted from other studies. ${ }^{34-36}$

These suggested that it is plausible to enhance nutritional knowledge in order to correct the perception and eventually improve nutritional practices among pregnant women in our population. However, other studies showed opposing findings, and they concluded of other circumstances in determining nutritional practices in their population. Traditional and cultural practices related to dietary intake of mothers which perceived as nutritious and healthy in community play the main role in their diet adequacy. ${ }^{34}$

Concerning attitudes, our study exhibits the relationship between attitude and practices were insignificant, in contrary to another similar study done. ${ }^{13}$ This could be attributed to the lack of statistical power of our study.

\section{CONCLUSION}

In conclusion, our result suggests that maternal education is the single most important predictor that may influence nutritional knowledge and practice. However, there was no significant relationship between education and nutritional attitude, as attitude may be inborn with them considering one's different upbringing. Thus it is 
crucial for a mother to be educated, as this will confer good knowledge, attitude, and practice during the upbringing of their children to prevent vicious circle of poor nutritional attitude. Maternal nutritional attitude is important in ensuring good attitude for her future generation. This is as proved by a model found a clear influence on how children both think and act around food, with consistent associations found between parent's and children's eating behaviors and attitudes. ${ }^{43}$

Our study results emphasize the importance of empowering girls and women with proper adequate educations and to strengthen the nutritional and health education of our educational system. Hence, the rights of mothers in getting the necessary and adequate education should be fulfilled. It is for them to be in a knowledgeable state with a good attitude and practicing healthy nutritional lifestyle as they enter their reproductive life, maintaining and transferring at least optimum healthy life to their progenies.

By conducting this study more education regarding nutrition in pregnancy need to be enhanced, as this will also help pregnant women to choose a healthy diet for safe pregnancy. Thus, this study will in turn help government in initiating intervention as early as before embarking the pregnancy period, targeting the appropriate group, especially the poorly educated women. Ultimately, it is our wish that more campaigns on promulgating the right message on nutrition as well as to upsurge awareness on healthy nutritional KAP during pregnancy in the community.

In view of the inability to establish an absolute categorization between good and poor nutritional KAP, we recommend those who wish to pursue a similar study to prefer tools that can confidently delineate this matter. It is also recommended that future tool to be more extensive as to allow a much clearer categorization. Other factors such as husband's education, husband's income, social support, parity, and traditional and cultural practices, which may have a relationship in determining one's nutritional KAP should be further explored. Since study about nutritional KAP is still lacking in our population especially among pregnant mothers, it is highly hoped that future research may be conducted in a larger setting.

\section{REFERENCES}

1. David JPB, Kent LT. The obstetric origins of health for a lifetime. Clinical obstetric and gynaecology 2013; 56(3):511-519.

2. Gemeda D, Fekadu B, Wondu G, et al. Assessment of Knowledge of Pregnant Mothers on Maternal Nutrition and Associated Factors in Guto Gida Woreda, East Wollega Zone, Ethiopia. Journal of Nutrition \& Food Sciences 2013; 2(3):105-113.
3. Latifa MF, Manal HA, Nihal SS. Nutritional awareness of women during pregnancy. J Am Sci 2012; 8(7):494-502.

4. Anna L. Maternal and child nutrition in SubSaharan Africa: challenges and interventions. Proceedings of the Nutrition Society 2008; 67 (1):105-108

5. Leontine W, Karin AMK, Annabelle C, et al. Aboriginal teenage pregnancies compared with non aboriginal in south Australia 19951999. Australian and New Zealand Journal of Obstetrics and Gynaecology 2002; 42(2):187192

6. Neil JS, M J, Jo PH, et al. Maternal obesity and pregnancy outcome: a study of 287213

pregnancies in London. International Journal of Obesity \& Related Metabolic Disorders 2001; 25 (8).

7. Gemeda D, Fekadu B, Wondu G, et al. Assessment of Nutritional Practices of Pregnant Mothers on Maternal Nutrition and Associated Factors in Guto Gida Woreda, East Wollega Zone, Ethiopia. Science. Technology and Arts Research Journal 2013; 2(3):105-113.

8. Gary M. Normal fetal growth and development. In: Obstetrics by Ten Teachers. London: Arnold, 2011:38.

9. Malgorzota SMG, Susan EO. Maternal nutrition during pregnancy and health of the offspring. Biochemical Society Transactions 2006; 34 (5):779-782.

10. Udipi SA, Ghugre $P$, Antony U. Nutrition in pregnancy and lactation. Journal of the Indian Medical Association 2000; 98(9):548-557.

11. Subarnalata S, Basumati P. A study of nutritional status of pregnant women of some villages in Balasore district, Orissa. J Hum Ecol 2006; 20:227-232.

12. Naomi M. Investigating health and nutrition messages given to pregnant women at Bwaila hospital in Lilongwe 2010.

13. Arega M. Assessment Of Knowledge, Attitude And Practices Regarding Maternal Nutrition Among Pregnant Women Attending Antenatal Care Clinics In Public Hospitals In Addis Ababa, Ethiopia, 2015. 2016.

14. Md NH, M NIK, Md ZS. The Pregnant and Lactating Mother's KAP (Knowledge, Attitude and Practice) and Nutritional Care during Antenatal and Postnatal Period in Ukhia, Cox's Bazar, Bangladesh. Journal of Scientific Research 2016; 8(1):55-70.

15. Hidemi $T$, Nobuo $Y$, Akane $K$, et al. Nutritional status of pregnant and lactating women in Japan: A comparison with non-pregnant/nonlactating controls in the National Nutrition Survey. Journal of obstetrics and gynaecology research 2003; 29(2):96-103.

16. Zahara AM, Nuruljannah J, Yee ML, et al. Nutritional Status and Nutritional Knowledge of Malay Pregnant Women in Selected Private Hospitals in Klang Valley. Jurnal Sains Kesihatan Malaysia 2014; 12(2):53-62.

17. Jayachandran NV, James B, David MS. Modelling nutrition knowledge, attitudes, and 
diet-disease awareness: the case of dietary fibre. Statistics in medicine 1996; 15(1):23-35.

18. Lisa H, Gladys B, Amy S, et al. Association of cancer prevention-related nutrition knowledge, beliefs, and attitudes to cancer prevention dietary behavior. Journal of the American Dietetic Association 1997; 97(9):957-965.

19. Kathryn P, Jo W, Jane W. Demographic variation in nutrition knowledge in England. Health education research 2000; 15(2):163-174.

20. Jane W, Kathryn P, Jo W. Nutrition knowledge and food intake. Appetite 2000; 34(3):269-275.

21. Jean D, Nadine $M$, Dominique $C$, et al. Association between nutrition knowledge and nutritional intake in middle-aged men from Northern France. Public Health Nutrition 2001; 4(01):27-33.

22. Tineke DV, Christrophe M, Wim V, et al. Determinants of nutrition knowledge in young and middle-aged Belgian women and the association with their dietary behaviour. Appetite 2009; 52(3):788-792.

23. Mitra M, Wan AMWM, Affizal A, et al. Relationship between nutritional knowledge and healthy attitude and practice during pregnancy. Borneo Science 2012; 31.

24. Amy SH, Nancy JT, Kathleen RM. Intention to breastfeed in low-income pregnant women: The role of social support and previous experience. Birth 1998; 25(3):169-174.

25. Sakhile KSM, Shu-Janj JL. Nutritional knowledge, attitude, and practices among pregnant and lactating women living with hiv in the manzini region of Swaziland. Journal of health, population, and nutrition 2014; 32 (2):261.

26. Souad FE. Knowledge, behaviour and practices of pregnant women in Wollongong regarding folic acid and iodine nutrition after the introduction of a mandatory fortification program. 2013.

27. Fiona D, Monique L, Sonia B, et al. Exploring and optimising maternal and infant nutrition in North West Pakistan. Midwifery 2012; 28(6):831 $-835$.

28. Sheryl LR, Janet WR, Ken PK, et al. Dietary quality during pregnancy varies by maternal characteristics in Project Viva: a US cohort. Journal of the American Dietetic Association 2009; 109(6):1004-1011.

29. Sharon JH, Emily O, Jess H, et al. Misperceived pre-pregnancy body weight status predicts excessive gestational weight gain: findings from a US cohort study. BMC Pregnancy and Childbirth 2008; 8(1):1.

30. Eileen RF. Comparing pregnant women's nutritional knowledge to their actual dietary intake. MCN: The American Journal of Maternal/Child Nursing 2002; 27(3):171-177.

31. Elizabeth F, Jane A. Strategies for intervention: commentary and debate. The Journal of Nutrition 2003; 133(3):844S-847S.

32. O'Brien G, Davies M. Nutrition knowledge and body mass index. Health education research 2007; 22(4):571-575.
33. Wim V, Ilse DB. Dietary behaviour of pregnant versus non-pregnant women. Appetite 2007; 48 (1):78-86.

34. Yolanda MG. Cultural factors affecting diet and pregnancy outcome of Mexican American adolescents. Journal of Adolescent Health 1999; 25(3):227-237.

35. Malgorzata KW, Magdalena MW. Dietary knowledge and practice in pregnant women. Roczniki Panstwowego Zakladu Higieny 2001; 53(2):167-175.

36. Seda A. Nutritional Knowledge, Attitude and Practices among people living with HIV in Armenia: a cross-sectional survey. 2015.

37. E-siong T. Nutrition of Malaysians: where are we heading. Mal J Nutr 1999; 5(1\&2): 87-109.

38. E-siong T. Development and promotion of Malaysian dietary guidelines. Asia Pacific journal of clinical nutrition 2011; 20(3): 45561.

39. Seong-Ting C, Kah-Leong S, Azriani AR, Hans VR, Sakinah H. Development and pilot testing of nutrition knowledge, attitude and practice questionnaire in persons with disabilities (KAPnOKU) among trainers in rehabilitation centres, Malaysia. Pakistan Journal of Nutrition 2013; 12(8): 708.

40. Guoyao W, Fuller WB, Timothy AC, Cynthia JM, Thomas ES. Maternal nutrition and fetal development. The Journal of nutrition; 2004. 134(9): 2169-72.

41. Margeret C, Julie A. Micronutrients and the use of vitamin and mineral supplements during pregnancy and lactation. British Journal of Midwifery 2016; 24(6).

42. Christine AP, Rosa BF, Gloria G. Men of diverse cultures: Knowledge and Attitudes About Breastfeeding. Journal of Obstetric, Gynecologic \& Neonatal Nursing; 2002. 31(6): 673-79.

43. Rachael B, Jane O. Children's eating attitudes and behaviour: a study of the modelling and control theories of parental influence. Health education research; 2004. 19(3): 261-71. 